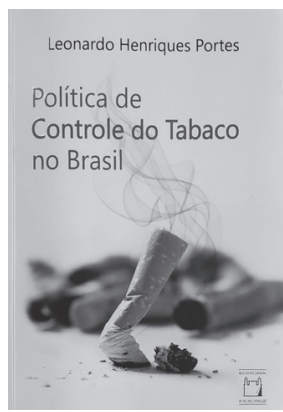

\title{
Portes LH. Política de controle do tabaco no Brasil
}

\author{
Mariana Pinho', Nilson do Rosário Costa1
}

DOI: 10.1590/0103-11042021129221

IN THE BOOK 'POLÍTICA DE CONTROLE DO TABACO NO BRASIL' (Tobacco control policy in Brazil), Leonardo Henriques Portes endeavors a five-chapter comprehensively analysis of the Brazilian tobacco control policy in the recent decades. In addition to describing the evolution of the smokers' predominance in Brazil and in America's countries, the book analyzes the government tobacco control policies in different countries worldwide. The authorl understands that those national policies enabled the consensus for the adoption of the WHO Framework Convention on Tobacco Control (FCTC) by 181 countries and the European Union. It was the first international tobacco control treaty, ratified by Brazil in 2005. According to the author, national initiatives were already being carried out when Brazil ratified the treaty. However, the commitment within WHO strengthened and broadened the scope of Brazilian policy.

The National Policy on Tobacco Control (PNCT) finds itself within the development complex context of the supranational regulatory public policies of risks to collective health, currently under strong pressure from ultra-right forces. Still, the author emphasizes the role of the Brazilian National Cancer Institute (Inca), headquartered in Rio de Janeiro, as the main entrepreneur of the PNCT agenda and manager of the National Commission for FCTC Implementation in Brazil (Conicq).

The issue of vetoing the PNCT propositions is lively addressed in the publication. The author affirms that the tobacco industry and allied entities were decisive for the veto of part of the policy measures.

Also the tensions concerning the referrals from the Sectorial Chamber of the Tobacco Production Chain, which relied on the participation of the federal and state governments until 2019, as the demonstrations and positioning of representatives of the Ministry of Agriculture, Development, Industry and Commerce and Labor and Employment held out against the commission proposals during most of the committee's trajectory.

In that context, Portes ${ }^{\mathbf{1}}$ addressed the limits and challenges of the main tobacco control measures in Brazil - especially those regarding crop diversification in tobacco cultivated areas, fighting illicit trade and interference of the tobacco industry in politics.

Portes $^{1}$ argues that the policy has achieved positive results due to the prestige of and Anvisa as references - and to the role of civil society. However, the author underlines that, as for politics, there remains the need to make progress in fighting illicit trade; 
in farmers supporting, so that they diversify their income and production; and in protecting them against the tobacco industry interests. With regard to governance, he believes that it is also necessary to overcome Conicq's limits of action and sustainability mechanisms.

The content of the book both allows the reader to understand the dimensions of tobacco control and accredits the deserved prominence to the actors and key institutions that contributed to achieve the numerous results. It also collaborates to assimilate that a successful public policy relies on a constitutional framework and solid foundations, as well as on articulated and intersectoral actions. The author moved from the role of observer to that of PNCT collaborator by means of disseminating his research and systematizing the findings.

The period of analysis lasted until 2016, the reason why it did not record PNCT recent, however relevant, moments. Among them, we underline the limited attempt of the federal government to carry on the National Diversification Program in 2018, and, more recently, in April 2019, the extinction of all collegiate bodies, including Conicq and the commission created in the previous year to implement the Protocol to Fight Illicit Trade of Tobacco Products. In 2020, the new structuring of the Sector Chambers of the Ministry of Agriculture was registered, and they no longer rely on the governmentl representativeness. It is also emphasized that the 2019 Vigitel telephone survey recorded an increase of 0.5 percentage points in the previous year as for the predominance of Brazilian smokers, shifting a trend of decline that lasted for more than ten years.

That conjuncture may result in a significant setback in the public tobacco control policy. The hope is that other democratic bodies, such as Federal Legislative and Judicial powers, together with civil society, which advocates for the right to health, will manifest for the Commission resurgence. The time is now to demand the resumption of Conicq's functions, since the tobacco industry regulation still needs to be broadened in Brazil. The book 'Política de controle do tabaco no Brasil' contains solid discussion in defense of that public policy and deserves to be read and celebrated.

\section{Collaborators}

Pinho M (0000-0002-8372-9272)* and Costa NR (0000-0002-8360-4832)* contributed equally to the preparation of the manuscript.

\section{Reference}

1. Portes LH. Política de controle do tabaco no Brasil.

Rio de Janeiro: Fiocruz; 2020.

\footnotetext{
Received on 07/31/2020

Approved on 10/20/2020

Conflict of interests: non-existent

Financial support: non-existent
} 